\title{
Development of effective construction and justification of parameters of the cleaner of fibrous material
}

\author{
Anvar Djuraev ${ }^{1 *}$, Ruzimurad Rosulov ${ }^{1}$, Javlon Kholmirzaev ${ }^{2}, H_{\text {usan }}$ Diyorov $^{3}$, and Umid \\ Berdimurodov $^{3}$ \\ ${ }^{1}$ Tashkent Institute of Textile and Light Industry, 100100 Tashkent, Uzbekistan \\ ${ }^{2}$ Namangan Institute of Engineering and Construction, 169101 Namangan, Uzbekistan \\ ${ }^{3}$ Termiz Branch of Tashkent State Technical University, 190100 Termiz, Uzbekistan
}

\begin{abstract}
This article provides a general scheme of the principle of operation of a fibrous material cleaner from coarse and fine litter. Based on the compilation of dynamic and mathematical models, its numerical solution, the regularities of the movement of the working bodies of the purifier are presented. Analyzes of the laws of motion and graphic dependencies substantiated the main parameters of the purifier. Recommendations are given for widespread use in fiber-cleaning production.
\end{abstract}

\section{Introduction}

The process of cleaning raw cotton from weed and foreign impurities is determined by the nature of its contamination and the effectiveness of the working bodies of the cleaners $[1,2]$. The cleaners are divided into machines for separating large trash impurities from raw cotton (cotton stalks, boll, flap, etc.) and machines for separating small trash (leaf particles, bracts, flowers, and dust) $[3,4]$.

The efficiency of removing weeds from raw cotton largely depends on the quality features inherent in this selective cotton variety, industrial varieties and moisture content of cotton, fiber length, the residence time of weeds in raw cotton, trash adhesion characteristics and many other indicators [5].

In the known design of the raw cotton cleaner from large litter, the grates are multifaceted and their ribs are curvilinear, while the angle of rotation of the edges of the face of one end of the tetrahedral grate relative to the other end is $45^{\circ}$, with the pentahedral grate $36^{\circ}$ and with the hexagonal grate $30^{\circ}$, the direction of rotation of the face of the neighboring grates opposite $[6,7]$.

The main disadvantage of this design is significant damage to cotton seeds due to the large angle of rotation of the grate ribs, a significant increase in the inhibition of the cotton fly [8]. In another design of the grate, containing a pair of sidewalls with holes and space between the sidewalls are rod grates, on the end section of the axis of which elastic

\footnotetext{
${ }^{*}$ Corresponding author: anvardjuraev1948@mail.ru
} 
bushings are installed, located in the holes of the sidewalls [9, 10]. The disadvantage of this design is the large escape of the fumes into the trash outlet due to the deformation of the elastic supports and an increase in the gap between the grates [11].

In the CCC purifier, there are pegs drums containing a zone for cleaning cotton from fine litter and a grid under them, a zone for cleaning cotton from coarse debris alternating with them, containing serrated drums and a grate under them, a stationary brush $[12,13]$. The disadvantage of this design of a combined cotton cleaner (CCC) is that it catches small trash impurities and merges with large trash in which there are volatiles of raw cotton. In addition, the CCC purifier does not have a sufficiently high efficiency of cleaning raw cotton, both fine and coarse litter [14, 15].

In order to remove small and large trash impurities separately and increase the cleaning effect, the design of the elements of the zones for small and large cotton cleaning was improved [16].

\section{Materials and Methods}

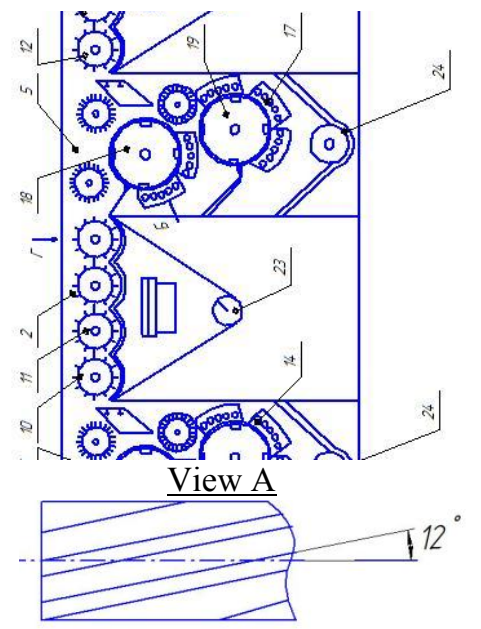

View B

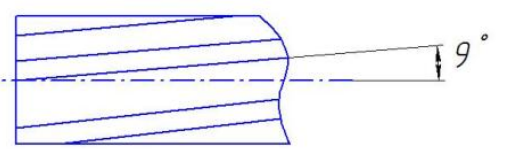

$\underline{\text { View C }}$

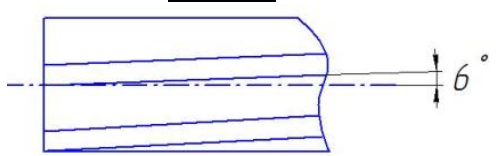

$\underline{\text { View D }}$ 


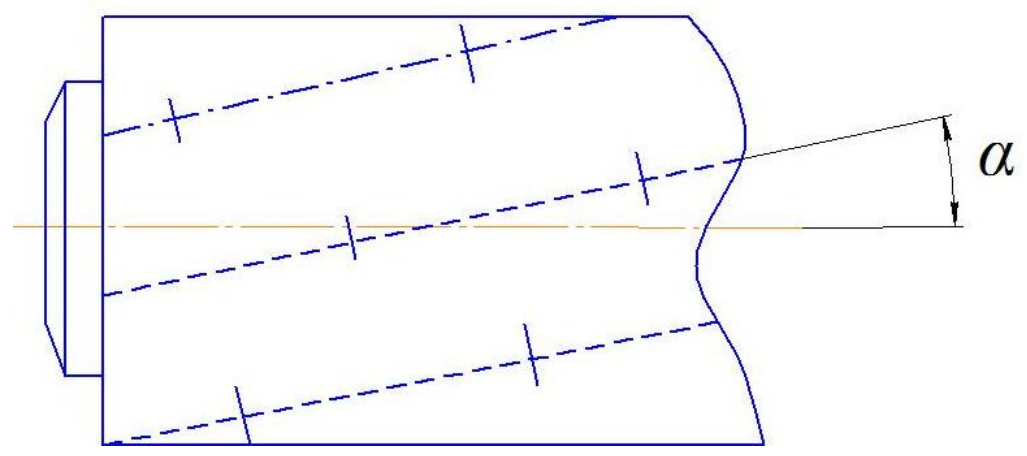

Fig. 1. Diagram of a fibrous material cleaner

The fibrous material cleaner contains 1,2,3 zones for cleaning cotton from fine debris and 4,5,6 zones for cleaning cotton from coarse debris (Fig. 1) [17]. Above the first zone 1, feed rollers 7 are installed. In this case, the pegs 8 of drums 9 of zone 1 are installed along a helical line at an angle $\alpha=30^{\circ}$, in the second zone 2, the pegs 10 of drums 11 are installed along a helical line at an angle of $\alpha=22.5^{\circ}$, and the third zone is 3 pegs 12 of drums 13 are installed along a helical line at an angle $\alpha=15^{\circ}$. In zone 4 , the polyhedral grate 14 under the serrated drums 15 and 16 are made with an angle of rotation of the ribs $12^{\circ}$ relative to the axis of the grate 14 , in zone 5 the ribs of the grate 17 under the serrated drums 18,19 are rotated by 90 , and in zone 6 the ribs of the grate 20 under the serrated drums 21,22 are rotated at an angle of $6^{\circ}$. Small trash impurities are removed by the augers 23 , and large trash impurities through the augers 24 . The working bodies are installed in the housing 25 .

The raw cotton cleaner works as follows. The raw cotton is fed through the feed rollers 7 into the first zone 1 to the peg drum 9, the pegs of which, set along a helical line by $30^{\circ}$, capture and drag the cotton effectively and loosens it. At the same time, in zone 1, the raw cotton is less loosened and therefore, due to the large screw angle, the cotton is exposed both in the circular and axial directions. At the same time, the opposites of the screw of adjacent peg drums, the cotton is subjected to a complex movement. In zone 4 of the grate 14 under the serrated drums 15 and 16 , when cotton interacts with them, multidirectional reaction forces occur with sufficient values due to the large angle of rotation $12^{\circ}$ of the grate 14 ribs, efficient separation of large litter occurs.

Further, in the 2nd, 5th, 3rd and 6th zones, cotton is cleared in a similar way. But, at the same time, in the course of movement of raw cotton through these zones, the angle of ascent of the helical line $\alpha$ of the installation of the pegs on the surfaces of the drums decreases to $15^{\circ}$, and the angles of inclination of the ribs of the multifaceted grates also decreases to 60 . That is, with the movement of cotton sequentially through the zones from 1 to 6 there is a gradual loosening of the cotton and therefore the slowdown of the cotton to advance also gradually decreases.

The isolated small weed impurities in the 1st, 2nd and 3rd zones are removed by the augers 23 , and the isolated large weed impurities in the 4th, 5th and 6th zones are removed by the augers 24 .

Combined cotton cleaner allows to increase the cleaning effect on fine and coarse dirt up to $(20-25) \%$ relative to the CCC cleaner.

In the recommended cotton cleaner, one of the main elements is considered to be the fine cotton cleaning zone. At the same time, it is important to select the parameters of the tuning drums that provide an increase in the cleaning effect. To establish the necessary operating modes for the peg drums, as well as to establish smooth transient modes of their 
movement, a separate electric motor was installed. Fig. 2 shows a dynamic model of a machine unit with drive mechanisms for the peg drums of the recommended fiber material cleaner using the methodology presented in $[5,6,7]$.

According to the dynamic model of the machine unit in Fig. 2. The system is five-mass with two branches. The movement from the engine is simultaneously transmitted to the first and second peg drums, then from the second peg drum to the third and fourth peg drums. In this case, the rotational speed of each subsequent drum is selected larger by (10-12) rpm than the previous one. At the same time, it has the ratio: $\dot{\varphi}_{d}=101.52 \mathrm{c}^{-1} ; \dot{\varphi}_{1}=43.0 \mathrm{c}^{-1}$; $\dot{\varphi}_{2}=46.5 \mathrm{c}^{-1} ; \dot{\varphi}_{3}=48.8 \mathrm{c}^{-1} ; \dot{\varphi}_{4}=52.95 \mathrm{c}^{-1}$; and $\mathrm{P}=7.5 \mathrm{kWt}$.

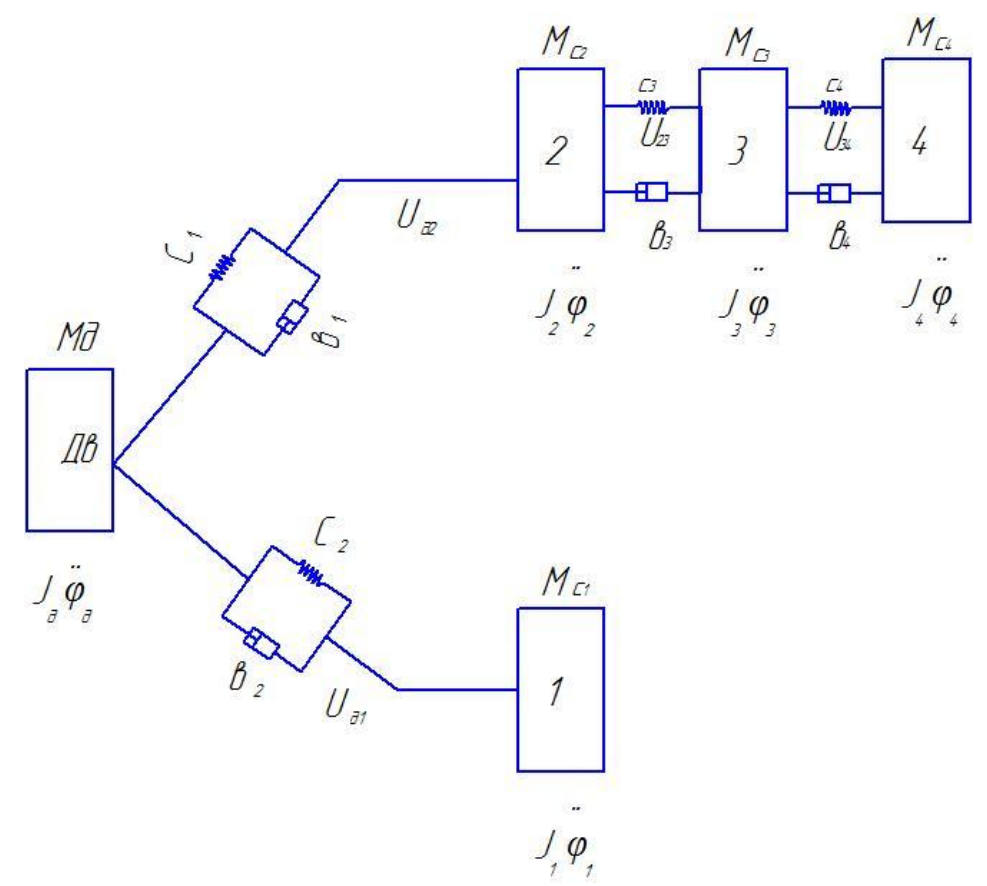

Fig. 2. Dynamic model of the machine unit of the fine cleaning zone drive

Taking into account the loading of the tuner drums installed in series, a diagram is drawn, which is shown in Fig. 3. Analysis of the histograms in Fig. 3. shows that in each subsequent peeling drum, the load from the raw cotton being cleaned gradually decreases. At the same time, the degree of loosening of the raw cotton increases, as well as the highspeed mode of operation of the peg drum. 


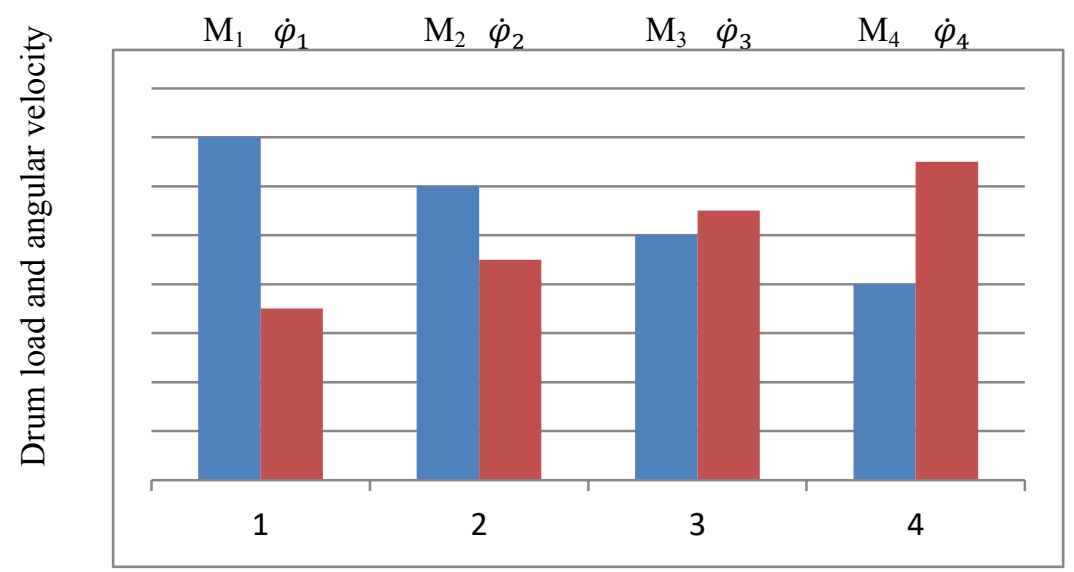

Pedestal drum numbers

Fig. 3. Pedestal drum loading

Using the methodology of compiling mathematical models of machine units of drives of technological machines according to $[8,9,10]$, we obtain the following system of differential equations for the considered zone of cleaning cotton from fine litter of the cleaner:

$$
\begin{gathered}
\frac{d M_{d}}{d t}=\left(\omega_{c}-P \frac{d \varphi_{d}}{d t}\right) \psi-\frac{M_{d}}{\mathrm{~T}_{e}} ; \\
\frac{d \psi}{d t}=\frac{2 \mathrm{M}_{\mathrm{K}}}{\mathrm{T}_{e}}\left(\omega_{c}-P \frac{d \varphi_{d}}{d t}\right)-M_{d} ; \\
\mathrm{T}_{e}=\left(\omega_{c}-S_{k}\right)^{-1} ; \psi=\frac{S_{k}}{S}\left(M_{d}+\mathrm{T}_{\ni} \frac{d M_{d}}{d t}\right) ; \\
J_{d} \frac{d^{2} \varphi_{d}}{d t^{2}}=M_{d}-\mathrm{B}_{1}\left(\frac{d \varphi_{d}}{d t}-U_{d 1} \frac{d \varphi_{1}}{d t}\right)-C_{1}\left(\varphi_{d}-U_{d 1} \varphi_{1}\right)-\mathrm{B}_{2}\left(\frac{d \varphi_{d}}{d t}-U_{d 2} \frac{d \varphi_{2}}{d t}\right)- \\
C_{2}\left(\varphi_{d}-U_{d 2} \varphi_{2}\right)-\mathrm{M} ; \\
J_{1} \frac{d^{2} \varphi_{1}}{d t^{2}}=U_{\mathrm{A} 1} \mathrm{~B}_{1}\left(\frac{d \varphi_{d}}{d t}-U_{d 1} \frac{d \varphi_{1}}{d t}\right)-U_{d 1} C_{1}\left(\varphi_{d}-U_{d 1} \varphi_{1}\right)-\mathrm{M}_{\mathrm{c} 1} ; \\
\frac{d^{2} \varphi_{2}}{d t^{2}}=U_{d 2} \mathrm{~B}_{2}\left(\frac{d \varphi_{d}}{d t}-U_{d 2} \frac{d \varphi_{2}}{d t}\right)-U_{d 2} C_{2}\left(\varphi_{d}-U_{d 2} \varphi_{2}\right)-\mathrm{B}_{3}\left(\frac{d \varphi_{2}}{d t}-U_{23} \frac{d \varphi_{3}}{d t}\right) \\
-C_{3}\left(\varphi_{2}-U_{23} \varphi_{3}\right)-\mathrm{M}_{2} \\
J_{3} \frac{d^{2} \varphi_{4}}{d t^{2}}=U_{34} \mathrm{~B}_{4}\left(\frac{d \varphi_{3}}{d t}-U_{34} \frac{d \varphi_{4}}{d t}\right)-U_{34} C_{4}\left(\varphi_{3}-U_{34} \varphi_{4}\right)-\mathrm{M}_{\mathrm{c} 4} \\
\left.C_{23} \mathrm{~B}_{3}\left(\frac{d \varphi_{2}}{d t}-U_{23} \frac{d \varphi_{3}}{d t}\right)+U_{23} C_{3}\left(\varphi_{2}-U_{23} \varphi_{3}\right)-U_{34} \varphi_{4}\right)-\mathrm{B}_{d} ;
\end{gathered}
$$


where $-M_{д}, M \kappa$ are the driving moment and its critical value on the motor shaft; $\omega_{c}$-circular frequency of the network; $\mathrm{P}$ is the number of pole pairs; $\varphi_{\text {д }}$-angular displacement of the motor rotor; $\mathrm{S}_{\mathrm{k}}$-critical slip; $\mathrm{T}_{3}$ is the electromagnetic time constant of the motor; $\psi$ auxiliary variable; $\varphi_{1}, \varphi_{2}, \varphi_{3}, \varphi_{4}$ - respectively angular displacement of the peg drums; $J_{\mathcal{A}}, J_{1}$, $\mathrm{J}_{2}, \mathrm{~J}_{3}, \mathrm{~J}_{4}$ - moments of inertia of the engine and peg drums; $\mathrm{C}_{1}, \mathrm{C}_{2}, \mathrm{C}_{3}, \mathrm{C}_{4}$ - respectively, the coefficients of the circular stiffness and dissipation of the belt drives of the drive to the peg drum of the cleaner; Uд1, U12, U23, U34 - gear ratios of the corresponding belt drives; and, $\mathrm{M}_{\mathrm{c} 1}, \mathrm{M}_{\mathrm{c} 2}, \mathrm{M}_{\mathrm{c} 3}, \mathrm{M}_{\mathrm{c} 4}$ - technological resistances from the cotton being cleaned to the peg drums according to the histograms in Fig. 2 which were obtained by experiments $[11,12]$.

\section{Results and Discussion}

On the basis of the numerical solution of system (1), the regularities of changes in the angular velocities of the movement of the electric motor rotor, peg drums, torque on the motor shaft from variation, technological resistances, and the stiffness coefficients of the drive belt drives were obtained.

Fig. 4 shows the characteristic patterns of change in $\dot{\varphi}_{d}, \mathrm{M}_{d}, \dot{\varphi}_{1}, \dot{\varphi}_{2}, \dot{\varphi}_{3}, \dot{\varphi}_{4}$. The analysis of the obtained laws of motion of the engine rotor and peg drums shows that the system reaches the steady-state operating mode in $(0.2-0.25 \mathrm{sec})$, taking into account the technological resistance from raw cotton. In this case, high-frequency fluctuations in angular velocities correspond to the frequency of rotation of the peg drums and the number of peg rows in the drum. So, in Fig. 4a, the laws of change in $\mathrm{M}_{\mathrm{d}}$ И $\dot{\varphi}_{d}$ are shown in time, and in Fig. $4 \mathrm{~b}$ shows the patterns of variation of $\dot{\varphi}_{1}, \dot{\varphi}_{2}, \dot{\varphi}_{3}$ and $\dot{\varphi}_{4}$ over time. Average values of angular velocities correspond to nominal values at average technological load.

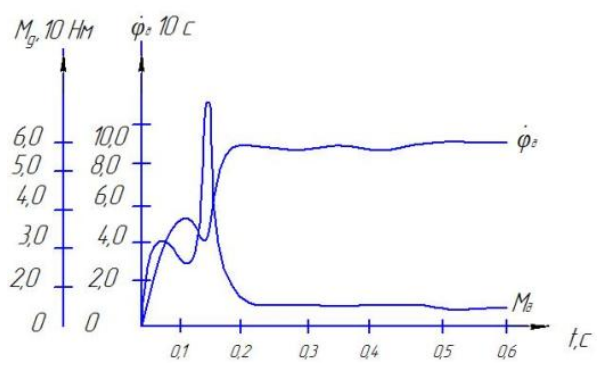

$\mathrm{a}$

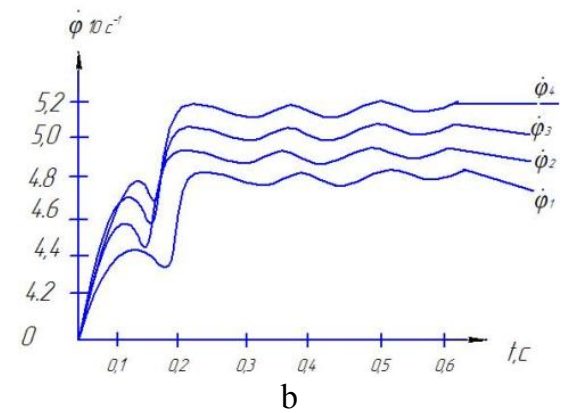

Fig. 4. Regularities of changes in the angular speed of the motor shaft (a) and peg drums (b), the load on the engine $t$ time

By processing the obtained laws of change in the angular velocities of the peg drums and the engine load, graphical dependences of the parameters of the machine unit were built. Fig. 5 shows the graphical dependences of the change in the coefficient of unevenness of the peg drums, the engine rotor and the torques on the engine shaft on the change in the technological resistance in the corresponding shafts.

The analysis of the obtained graphical dependencies shows that an increase in the productivity of the cleaner in the area of fine cleaning of cotton leads to an increase in the engine load, as well as the unevenness of the angular velocities of the peg drums and the rotor according to a nonlinear pattern. So, with an increase in Mc from $0.310 \mathrm{Nm}$ to 1.810 $\mathrm{Nm}$, the moment $\mathrm{M}_{\mathrm{d}}$ increases from $3.2 \mathrm{Nm}$ to $29.2 \mathrm{Nm}$. In this case, $\delta \mathrm{d}$ increases from 0.041 to 0.056 . In this case, the coefficient of unevenness of the angular velocity of the first peg drum increases from 0.046 to 0.135 , and of the fourth peg drum from 0.022 to 0.072 according to a nonlinear pattern. It should be noted that in the initial zone, the first and 
second peg drums experience large loads (see Fig. 2, histograms) due to the small looseness of the cotton being cleaned, and then the loads on the peeled drums 3,4 will be significantly less due to the sufficient loosening of the cotton. The recommended values are: $\delta_{1}=$ $(0,03 \div 0,035) ; \delta_{2}=(0,025 \div 0,028) ; \delta_{3}=(0,022 \div 0,024) ; \delta_{4}=(0,018 \div 0,02)$, and $\mathrm{Mc} \leq(2.0 \div 2.5) 10 \mathrm{Nm}$.

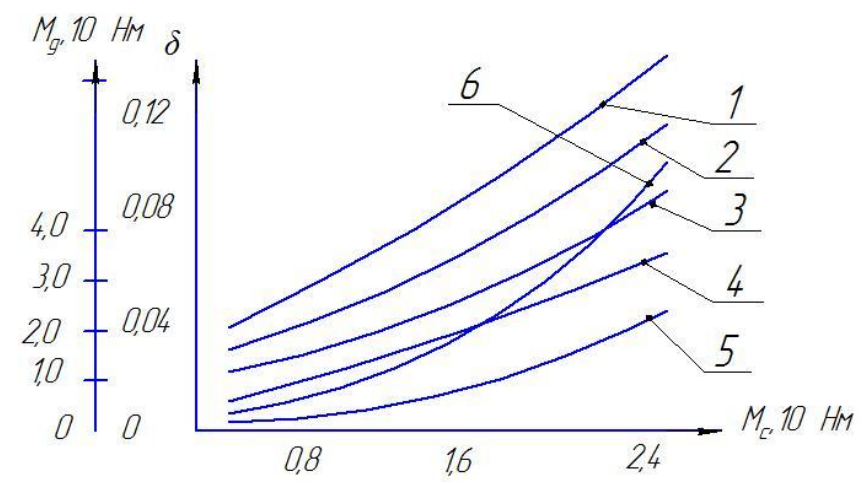

Fig. 5. Graphical dependences of the change in the unevenness coefficients of the peg drums, the engine rotor and the torque on the engine shaft on the change in the technological resistance in the corresponding shafts (where $1-\delta_{1}=\mathrm{f}\left(\mathrm{M}_{\mathrm{c} 1}\right) ; 2-\delta_{2}=\mathrm{f}\left(\mathrm{M}_{\mathrm{c} 2}\right) ; 3-\delta_{3}=\mathrm{f}\left(\mathrm{M}_{\mathrm{c} 3}\right) ; 4-\delta_{4}=\mathrm{f}\left(\mathrm{M}_{\mathrm{c} 4}\right)$; $\left.5-\delta_{\mathrm{d}}=\mathrm{f}\left(\mathrm{M}_{\mathrm{c}}\right) ; 6-\mathrm{M}_{d}=\mathrm{f}\left(\mathrm{M}_{\mathrm{c}}\right)\right)$

Fig. 6 shows graphical dependences of the change in the angular velocities of the peg drums on the change in the corresponding technological resistance. It is known that with an increase in technological resistance, that is, the productivity of the purifier, the speed modes of movement of the working bodies decrease accordingly. So, with an increase in Mc from $0.210 \mathrm{Nm}$ to $2.410 \mathrm{Nm}$, the angular velocity of the first peg drum decreases from $52.0 \mathrm{~s}^{-1}$ to $45.5 \mathrm{~s}^{-1}$ according to a nonlinear pattern. As noted above, for the elimination of bottoms in the area of cleaning raw cotton from fine litter, the angular velocity of each subsequent drum will be greater than the previous one. It can be seen from the graphs in Fig. 6 that with an increase in the productivity of the raw cotton cleaner, the angular velocity of the last fourth peel drum decreases from $43.1 \mathrm{~s}^{-1}$ to $34.2 \mathrm{~s}^{-1}$. This means that each subsequent peg drum will be faster than the previous one and the driving mode will be smoother.

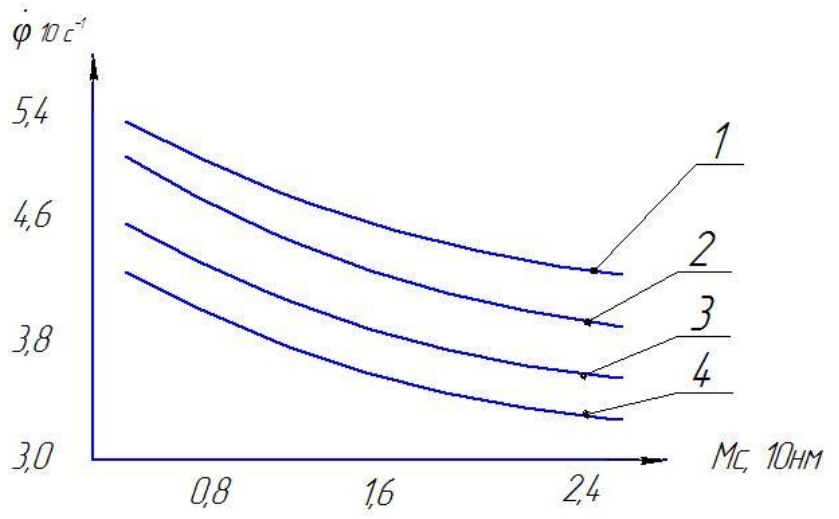

Fig. 6. Graphical dependences of the change in the angular velocities of the tuning drums on the change in the corresponding technological resistance (where $1-\dot{\varphi}_{1}=\mathrm{f}\left(\mathrm{M}_{\mathrm{c}_{1}}\right) ; 2-\dot{\varphi}_{2}=\mathrm{f}\left(\mathrm{M}_{\mathrm{c}_{2}}\right)$; $3-\dot{\varphi}_{3}=\mathrm{f}\left(\mathrm{M}_{\mathrm{c}_{3}}\right) ; 4-\dot{\varphi}_{4}=\mathrm{f}\left(\mathrm{M}_{\mathrm{c}_{4}}\right)$ ) 
Fig. 7 shows the dependences of the change in the amplitude of oscillations of the angular velocities of the peg drums and the load on the engine on the change in the ratios of the circular stiffness coefficients of the corresponding belt drives to the peg drums. An increase in the circumferential rigidity of the belt drives of the cotton cleaner drive in the fine cleaning zone leads to an increase in the torque on the motor shaft according to nonlinear zoconometric patterns. So, with an increase in $\mathrm{C} / \mathrm{Cp}$ of the corresponding belt drive for both branches of the system (see Fig. 3) at $\mathrm{pr}=5 \mathrm{t} / \mathrm{h}$, the moment $\mathrm{Md}$ increases from 19.4 Nm to $62.3 \mathrm{Nm}$ according to a nonlinear pattern (see Fig. 8, curves 1 and 2). This is due to the fact that with an increase in the rigidity of the belt drives, in practice, the system becomes more integral, single with a large total moment of inertia. This, in turn, leads to a slight decrease in the oscillations of the angular velocities of the peg drums (see Fig. 8, curves 3-6). Therefore, to ensure the necessary fluctuations in the angular velocities of the peg drums, allowing the required cleaning of cotton from fine litter, as well as at the minimum values of the electric drive load, the recommended values are: $\mathrm{C} 1=(120 \div 139)$ $\mathrm{Nm} / \mathrm{rad} ; \mathrm{C} 2=(150 \div 170) \mathrm{Nm} / \mathrm{rad} ; \mathrm{C} 3=(200-250) \mathrm{Nm} / \mathrm{rad} ; \mathrm{C} 4=(300 \div 320) \mathrm{Nm} / \mathrm{rad} ; \mathrm{b} 1$ $=(8.0 \div 10) \mathrm{Nms} / \mathrm{rad} ; \mathrm{b} 2=(10 \div 12) \mathrm{Nms} / \mathrm{rad} ; \mathrm{b} 3=\mathrm{b} 4=(12.5 \div 14) \mathrm{Nms} / \mathrm{rad}$. With these recommended values of the parameters, the necessary effect of cleaning the raw cotton from fine litter is ensured at a high productivity of the machine without stopping in the cleaning zone.

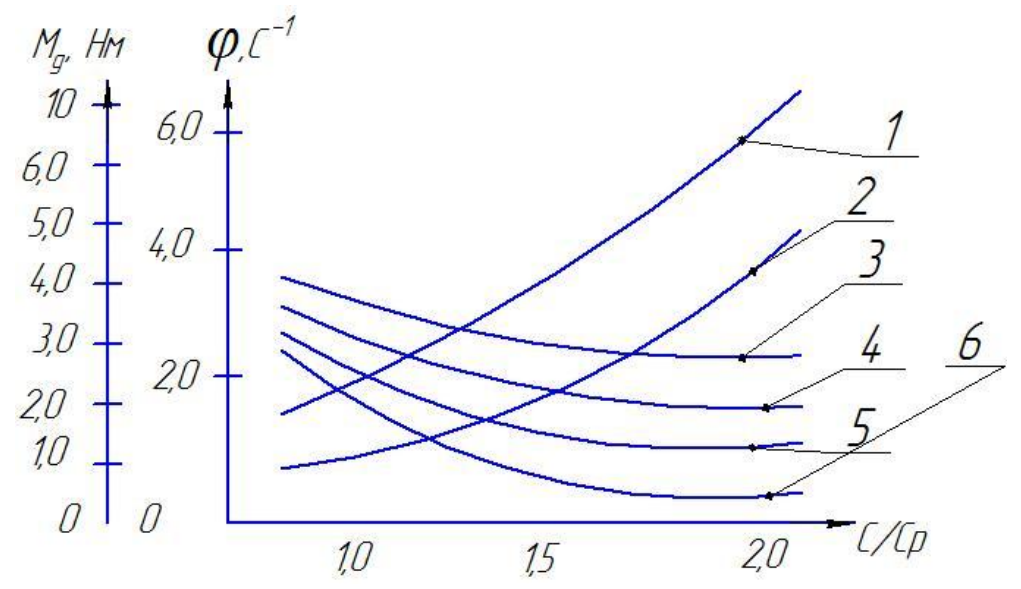

Fig. 7. Dependence of the change in the amplitude of oscillations of the angular velocities of the peg drums and the load on the engines on the change in the ratios of the circular stiffness coefficients of the corresponding belt drives and the peg drum (where $1-\mathrm{Md}$ at nd $=5 \mathrm{t} / \mathrm{h}, 2-\mathrm{MD}$ at nd $=3 \mathrm{t} / \mathrm{h}, 3$ $\Delta \dot{\varphi}_{1}=\mathrm{f}(\mathrm{C} / \mathrm{Cp}) ; 4-\Delta \dot{\varphi}_{2}=\mathrm{f}(\mathrm{C} / \mathrm{Cp}) ; 5-\Delta \dot{\varphi}_{3}=\mathrm{f}(\mathrm{C} / \mathrm{Cp}) ;$ and $\left.6-\Delta \dot{\varphi}_{4}=\mathrm{f}(\mathrm{C} / \mathrm{Cp})\right)$.

\section{Conclusions}

A new effective design scheme for a fibrous material cleaner has been developed and recommended. On the basis of research, the main parameters of the cleaner are substantiated, which provide the necessary effect of cleaning raw cotton from fine litter at a high productivity of the machine without faces in the cleaning zone.

\section{References}

1. V. Shcherbakov, Applied and structural mechanics of fibrous materials, 304 (Tisoprint Press, Moscow, 2013) 
2. W. Morton, J. Hearle, Physical properties of textile fibers, 765 (Cambridge Press, London, 2008)

3. I. Migushov, The mechanics of textile yarn and fabric, 160 (Light industry Press, Moscow, 1980)

4. S. Ismailova, K. Sultanov, Mechanics of Solids 5, 578-592 (2015)

5. K. Sultanov, S. Ismoilova, Journal of Fashion Technology \& Textile Engineering 10(3), 11 (2017)

6. K. Sultanov, S. Ismoilova, N. Mamatova, Journal of Fashion Technology \& Textile Engineering 6(1), 10 (2018)

7. K. Sultanov, S. Ismailova, Sh. Tulanov, Izvestiya Vuzov, Technology of the textile industry 5(365), 109-115 (2016)

8. S. Ismailova, K. Sultanov, Sh. Tulanov, Izvestiya Vuzov, Technology of the textile industry 4 (364), 63-67 (2016)

9. K. Sultanov, S. Ismailova, Izvestiya Vuzov, Technology of the textile industry 3(375), 95-101 (2018)

10. M. Agzamov, S. Yunusov, J. Gafurov, IOP Conference Series: Materials Science and Engineering 254(8), 082017 (2017)

11. M. Agzamov, Izvestiya Vysshikh Uchebnykh Zavedenii, Seriya Teknologiya Tekstil'noi Promyshlennosti 2007(1), 26-29 (2007)

12. M. Agzamov, M. Agzamov, G. Madgidov, Izvestiya Vysshikh Uchebnykh Zavedenii, Seriya Teknologiya Tekstil'noi Promyshlennosti 2007(3), 34-37 (2007)

13. R. Makhkamov, M. Agzamov, Izvestiya Vysshikh Uchebnykh Zavedenii, Seriya Teknologiya Tekstil'noi Promyshlennosti 2006(2), 101-104 (2006)

14. S. Yunusov, European applied sciences 3, 79-85 (2015)

15. G. Holt, W. Laird, The Journal of Cotton Science 11, 79-90 (2007)

16. A. Dzhuraev, S. Yunusov, A. Mirzaumidov, K. Umarov, A. Matkarimov, International Journal of Advanced Science and Technology 29(4), 1371-1390 (2020)

17. A. Djuraev, E. Narmatov, O. Murodov, T. Yormamatov, B. Olimjonov, Journal of Physics: Conference Series 1889(4), 042017 (2021) 